American Journal of Economics and Business Administration 3 (2): 405-409, 2011

ISSN 1945-5488

(c) 2011 Science Publications

\title{
Clay Vs. Grass: A Statistical Comparison of the French Open and Wimbledon
}

\author{
Michael R. Summers \\ Business Administration Division, \\ Pepperdine University Malibu, 9026, CA
}

\begin{abstract}
Problem statement: While most professional tennis tournaments today are played on hard courts, there is a short clay court season culminating in the French Open and an even shorter grass court season culminating in Wimbledon, where specialists on those surfaces have their chance to shine. Conventional thinking has it that these two surfaces play so differently that it is difficult for a player to succeed on both and this has largely proven true over the years. Approach: Performance statistics were collected from the French Open and Wimbledon in 2010 and analyzed. This study seeks to quantify the significant differences that exist in performance on these surfaces. Results: While the differences between the two tournaments have been reduced somewhat over the years, there remain significant differences. Conclusion/Recommendations: These results have implications both for professional tennis players and for the management of these tournaments.
\end{abstract}

Key words: Professional tennis, statistical analysis, sports management, performance measures

\section{INTRODUCTION}

Of the four major tennis championships in the world each year, both the U.S. Open and the Australian Open are played on hard courts, as are most tournaments throughout the year. Hard courts may present different playing conditions based on such things as temperature, humidity, wind, sun and the specific composition of the court, but overall they give the most consistent bounces and are thought to be the fairest test of tennis ability. The French Open is played on clay (actually crushed brick), which gives a slower, higher bounce, making it easier to strike the ball and more difficult for one player to hit a ball out of reach of the other or to force an error. Points on clay often consist of long rallies from the baseline. Wimbledon is played on grass, which plays "faster," giving a lower, more difficult and more inconsistent bounce. Traditionally, Wimbledon has favored big hitters with a strong serve-and-volley game; points often consist of either a service winner or just a few strikes of the ball.

Because of the difference in surfaces and the short time (just a few weeks) between the French Open and Wimbledon, it has been very difficult for players to excel in both. In fact, some top players, such as Pete Sampras at the French Open, have sometimes skipped one or the other because of the feeling that they had no hope of doing well. Sampras ranks second overall in Grand Slam titles with 14, but none of them were in the French Open. Similarly, Ivan Lendl was never able to win at Wimbledon, despite his 8 Grand Slam titles. The most notable exception to this rule was Bjorn Borg in the 1970's and early 1980's. He won 6 French Open titles and 5 Wimbledon titles, three times winning both in the same year. His strong topspin stroke was wellsuited both to clay and to grass, but he didn't win a single major championship on a hard court.

In recent years the disparity between the clay at the French and the grass at Wimbledon seems to have narrowed. In fact, in each of the last three years the same player has won both, Rafael Nadal in 2008 and 2010 and Roger Federer in 2009. Between them these two players have won the last 6 French Opens and the last 8 Wimbledons. Also during those years Federer was runner-up 3 times to Nadal at the French and Nadal was runner-up twice to Federer at Wimbledon. Part of the reason is certainly that these are two extraordinary players who have a good chance of winning any tournament they enter. Federer is the all-time leader in Grand Slam titles with 16 and Nadal's heavy topspin shots, like Borg's, are an advantage on both surfaces. However, another factor may be that the surfaces are no longer playing quite as differently as they have in the past. After complaints that the strength of the players and the new racquet technology had made points at Wimbledon too short and uninteresting, in 2001 the courts were completely replaced. The new grass was more durable, allowing the soil to be compacted more and providing for a slower, higher bounce, more similar to clay (Harrell, 2008). Players have also complained that the balls at Wimbledon have been made less lively over the years. According to Eddie Seaward, the head groundskeeper at Wimbledon for the last 20 years, the ball now comes off the ground at the same speed as before but does have a higher bounce, giving players an extra one-tenth of a second to hit it (Martin, 2010). This 
small amount of time, along with fewer bad bounces, can make a significant difference in the overall speed of the court.

Because of the changes in courts, balls, equipment and players over the years, this study examines a snapshot of the differences in performance in the Men's Singles events at the French Open and Wimbledon in 2010.

\section{MATERIALS AND METHODS}

Statistics are provided by IBM for both the French Open (Roland-Garros, 2010) and Wimbledon (Wimbledon Championships, 2010). While some of the percentage calculations on these websites were not accurate, it is assumed that the raw frequencies were correct. These statistics include overall performance measures for the entire tournament, including every point played, as well as performance measures for each match within the tournament.

The overall measures for each tournament may be thought of as exact parameters for that tournament, with no sampling error, since the population would be defined as the points played in that tournament. In that sense any differences between the two tournaments do describe the actual differences for those players on those days. However, in order to generalize, a more conservative and useful definition of the populations would be the set of all possible points generated by the players in each tournament. Thus, the actual points observed would form a (very large) random sample of points observed from that population and the common statistical tests of significance would apply. Similarly, the performance measures of the individual matches may be defined as statistics derived from sample points taken from a larger population of possible points from those players.

Of the 128 players in each tournament, 102 played in both the French and Wimbledon. Thus, the overall statistics of each event largely reflect the same players under different court conditions. To make direct comparisons, though, we have also compared the performance of the top ten players who played at both events.

\section{RESULTS AND DISCUSSION}

Table 1 shows overall performance measures for the French Open, broken down by round. Table 2 shows similar measures for Wimbledon. While there are ordinarily 127 matches in a field of 128 players, Wimbledon had only 126 matches because of a forfeiture by one player before the match started. There were also several matches at each tournament where a player had to retire before the end of a match because of injury. It is interesting to note that Wimbledon had more total points $(30,251-27,293)$, more total games $(4,974-4,328)$ and more total sets (479-457) than did the French. On the average, players played about 5 more games per match at Wimbledon. This could indicate that the matches were more evenly contested, possibly because of a greater server's advantage at Wimbledon. Because of these discrepancies, though, the most relevant statistics to compare the two tournaments would be in the form of percentages.

Table 3 shows the results of 9 hypothesis tests of the difference between relevant proportions at the two tournaments. The results are consistent with expectations and for the most part, are extremely significant statistically. As expected, the server won a significantly higher percentage of first-serve points at Wimbledon than at the French, a difference of more than 5 percentage points. The same was true of second-serve points, but with less significance. The overall percentage of points won by the server showed the same high level of significance, with a difference of over 4 percentage points.

Table 1: 2010 French open statistics -- Men's singles

\begin{tabular}{|c|c|c|c|c|c|c|c|c|c|}
\hline Round & $1 \mathrm{st}$ & 2nd & 3rd & 4th & Q-F & S-F & $\mathrm{F}$ & Total & Percent \\
\hline Matches played & 64.0000 & 32.0000 & 16.0000 & 8.0000 & 4.0000 & 2.0000 & 1.0000 & 127 & \\
\hline Sets played & 232.0000 & 115.0000 & 59.0000 & 25.0000 & 15.0000 & 8.0000 & 3.0000 & 457 & \\
\hline Tie breaks played & 30.0000 & 15.0000 & 7.0000 & 2.0000 & 3.0000 & 1.0000 & 0.0000 & 58 & 0.1269 \\
\hline Total games & 2198.0000 & 1084.0000 & 558.0000 & 234.0000 & 148.0000 & 78.0000 & 28.0000 & 4328 & \\
\hline Winners & 5972.0000 & 2873.0000 & 1466.0000 & 560.0000 & 382.0000 & 223.0000 & 75.0000 & 11551 & 0.4232 \\
\hline Return games won & 472.0000 & 261.0000 & 137.0000 & 58.0000 & 23.0000 & 17.0000 & 4.0000 & 972 & 0.2246 \\
\hline Server points won & 8691.0000 & 4277.0000 & 2174.0000 & 856.0000 & 614.0000 & 298.0000 & 119.0000 & 17029 & 0.6239 \\
\hline Total points & 13825.0000 & 6957.0000 & 3518.0000 & 1372.0000 & 961.0000 & 479.0000 & 181.0000 & 27293 & \\
\hline First serves in & 8278.0000 & 4253.0000 & 2217.0000 & 837.0000 & 598.0000 & 303.0000 & 120.0000 & 16606 & \\
\hline$\%$ 1st serves in & 0.5988 & 0.6113 & 0.6302 & 0.6101 & 0.6223 & 0.6326 & 0.6630 & & 0.6084 \\
\hline Total aces & 968.0000 & 411.0000 & 221.0000 & 83.0000 & 57.0000 & 46.0000 & 14.0000 & 1800 & 0.0660 \\
\hline Total double faults & 482.0000 & 193.0000 & 105.0000 & 24.0000 & 29.0000 & 19.0000 & 5.0000 & 857 & 0.0314 \\
\hline 1st serve pts won & 5895.0000 & 2928.0000 & 1503.0000 & 575.0000 & 424.0000 & 215.0000 & 84.0000 & 11624 & \\
\hline$\%$ 1st serve pts won & 0.7121 & 0.6885 & 0.6779 & 0.6870 & 0.7090 & 0.7096 & 0.7000 & & 0.7000 \\
\hline$\%$ 2nd serve pts won & 0.5041 & 0.4989 & 0.5158 & 0.5252 & 0.5234 & 0.4716 & 0.5738 & & 0.505 \\
\hline
\end{tabular}


Am. J. of Economics and Business Administration 3 (2): 405-409, 2011

Table 2: 2010 Wimbledon statistics -- Men's singles

\begin{tabular}{|c|c|c|c|c|c|c|c|c|c|}
\hline Round & 1st & 2nd & 3rd & 4th & $\mathrm{Q}-\mathrm{F}$ & S-F & $\mathrm{F}$ & Total & $\%$ \\
\hline Matches played & 64.0000 & 31.0000 & 16.0000 & 8.0000 & 4.0000 & 2.0000 & 1.0000 & 126 & \\
\hline Sets played & 238.0000 & 124.0000 & 62.0000 & 31.0000 & 15.0000 & 6.0000 & 3.0000 & 479 & \\
\hline Tie breaks played & 47.0000 & 27.0000 & 14.0000 & 4.0000 & 3.0000 & 2.0000 & 0.0000 & 97 & 0.2025 \\
\hline Total games & 2492.0000 & 1301.0000 & 630.0000 & 315.0000 & 141.0000 & 64.0000 & 31.0000 & 4974 & \\
\hline Winners & 7586.0000 & 3969.0000 & 1983.0000 & 950.0000 & 424.0000 & 170.0000 & 75.0000 & 15157 & 0.5010 \\
\hline Return games won & 426.0000 & 197.0000 & 85.0000 & 49.0000 & 24.0000 & 8.0000 & 4.0000 & 793 & 0.1594 \\
\hline Server points won & 10000.0000 & 5329.0000 & 2602.0000 & 1271.0000 & 585.0000 & 266.0000 & 120.0000 & 20173 & 0.6669 \\
\hline Total points & 15181.0000 & 7899.0000 & 3823.0000 & 1906.0000 & 892.0000 & 379.0000 & 171.0000 & 30251 & \\
\hline First serves in & 9626.0000 & 4972.0000 & 2382.0000 & 1169.0000 & 556.0000 & 245.0000 & 110.0000 & 19060 & \\
\hline$\%$ 1st serves in & 0.6341 & 0.6294 & 0.6231 & 0.6133 & 0.6233 & 0.6464 & 0.6433 & & 0.6301 \\
\hline Total aces & 1621.0000 & 948.0000 & 473.0000 & 216.0000 & 91.0000 & 39.0000 & 18.0000 & 3406 & 0.1126 \\
\hline Total double faults & 515.0000 & 265.0000 & 115.0000 & 82.0000 & 31.0000 & 14.0000 & 3.0000 & 1025 & 0.0339 \\
\hline 1 st serve pts won & 7162.0000 & 3760.0000 & 1863.0000 & 890.0000 & 413.0000 & 190.0000 & 83.0000 & 14361 & \\
\hline$\%$ 1st serve pts won & 0.7440 & 0.7562 & 0.7821 & 0.7613 & 0.7428 & 0.7755 & 0.7545 & & 0.7535 \\
\hline$\%$ 2nd serve pts won & 0.5109 & 0.5360 & 0.5128 & 0.5170 & 0.5119 & 0.5672 & 0.6066 & & 0.5193 \\
\hline
\end{tabular}

Table 3: Tests of differences in proportions

\begin{tabular}{llllrr}
\hline \multicolumn{1}{c}{} & French & Wimbledon & Pooled proportion & $\mathrm{z}$ & 1-tailed $\mathrm{p}$ \\
\hline Tie breaks played & 0.126915 & 0.202505 & 0.165598 & -3.109850 & $<0.001$ \\
Winners & 0.423222 & 0.501041 & 0.464132 & -18.691000 & $<0.001$ \\
Return games won & 0.224584 & 0.159429 & 0.189744 & 7.993948 & $<0.001$ \\
Server points won & 0.623933 & 0.666854 & 0.646497 & -10.754400 & $<0.001$ \\
\% 1st serves in & 0.608434 & 0.630062 & 0.619804 & -5.336660 & $<0.001$ \\
Total aces & 0.065951 & 0.112591 & 0.090470 & -19.475900 & $<0.001$ \\
Total double faults & 0.198013 & 0.206072 & 0.032705 & -1.672300 & $<0.050$ \\
\% 1st serve pts won & 0.699988 & 0.753463 & 0.728565 & -11.327900 & $<0.001$ \\
\% 2nd serve pts won & 0.505755 & 0.519346 & 0.512707 & -2.010430 & $<0.025$ \\
\hline
\end{tabular}

The percentage of aces zoomed from $6.6 \%$ of all points at the French to $11.3 \%$ at Wimbledon, a huge difference. The percentage of points won by hitting outright winners, including aces, was also significantly higher at Wimbledon, by almost 8 percentage points. Therefore, both on the serve and during rallies we can see the effects of the greater speed of the grass court. Overall, then, it was much more difficult to break serve at Wimbledon, just $15.9 \%$ of the time as opposed to $22.5 \%$ of the time at the French.

There are several other, less obvious, differences at the two tournaments. The percentage of sets that go to tiebreakers was much higher at Wimbledon, 20.3-12.7\%. Because of the difficulty in breaking serve at Wimbledon, this seems reasonable. However, we also see significant effects on service accuracy that are unexpected. Why do servers at Wimbledon get a significantly higher percentage of their first serves in (63.0-60.8\%)? Are they able to serve at slower speeds and get more serves in because their serves are harder to return? Later we will examine service speed of individuals at the two tournaments. While getting more first serves in, servers at Wimbledon nevertheless tended to have more double faults than at the French, at a marginally significant level. Perhaps servers are willing to try for a harder second serve because they know that they have a large advantage in serving and are less afraid of giving up a point through double-faulting.
Table 4 shows performance measures for the top ten players that played at both tournaments. For each of these measures a paired-sample t-test was performed to determine whether the average change of the individual players on that measure between the French and Wimbledon was significant.

While 102 players competed in both tournaments, the other 26 players at each were selected by the host country and perhaps were chosen because their games were better suited either to clay or to grass. In that case these players may have had some effect on the overall statistics. Therefore, this comparison of individual players who played in both tournaments should add to the picture.

Although the percentage of first serves in was significantly higher at Wimbledon for the entire field, in our comparison for the top ten players there was no significant difference. The top ten players at the French had a higher percentage of first serves in than did the rest of the field, so their average at the French was virtually identical to their average at Wimbledon, which in that case was very similar to the overall field.

The top ten players won significantly more firstserve points at Wimbledon than at the French, as did the overall field. However, the top players won about $3 \%$ more of their first-serve points at both places than did the overall field. On the second serve the 
percentage of points won was not significantly higher at Wimbledon, while for the overall field it was. Since the paired-sample t tests had a sample size of only 10 , it was much harder to prove that the differences were significant.

The percentage of net approaches won by the top ten players was a little higher at Wimbledon, but not enough to be significant. In both cases net approaches resulted in winners about $2 / 3$ of the time. While there were probably a lot more net approaches at Wimbledon, those that were made at the French were most likely in situations that also had a high probability of resulting in a winning shot. This statistic was not available for the overall field.

One of the most interesting comparisons between the French and Wimbledon is the average serving speed. The serve is hit, of course, before the court surface has any chance to affect the ball. However, it often seems that players are hitting their serves harder at Wimbledon than at the French (adding to the difficulty of the receiver, who already has to face a faster bounce). The firmness of the footing could have some effect and the balls tend to pick up particles of clay at the French, making them heavier.

There could also be an intentional strategic difference in the amount of speed a player applies to his serve at the two tournaments. For the top ten players there was indeed a small increase in average serve speed at Wimbledon, up from 116.23-117.84. However, with a one-tailed p-value of .1091 , this difference was not significant. On the other hand these players hit their second serves about $4 \mathrm{MPH}$ faster at Wimbledon, up from $95 \mathrm{MPH}$ at the French, a very significant increase in speed.

The top ten players differed quite a bit in their average first serve speed, from Verdasco's average of 105.27 MPH to Soderling's average of 126.63 MPH at the French and from Ferrer's 112.27 MPH to Soderling's 125.92 MPH at Wimbledon. While we might expect that those players with the faster serves would have a lower percentage of first serves in, there was no significant relationship between the two measures, either at the French or at Wimbledon (Table 5).

Table 4: Individual comparisons

\begin{tabular}{|c|c|c|c|c|c|c|}
\hline Player & $\%$ 1st Serves in & $\begin{array}{l}\% \text { 1st Serve } \\
\text { Points won }\end{array}$ & $\begin{array}{l}\% \text { 2nd Serve } \\
\text { Points won }\end{array}$ & $\begin{array}{l}\text { \% Net } \\
\text { Approaches won }\end{array}$ & $\begin{array}{l}\text { Ave. 1st Serve } \\
\text { Speed (MPH) }\end{array}$ & $\begin{array}{l}\text { Ave. 2nd Serve } \\
\text { Speed (MPH) }\end{array}$ \\
\hline Federer-French & 0.6400 & 0.7690 & 0.5950 & 0.7550 & 119.7100 & 97.8700 \\
\hline Federer-Wimb. & 0.6350 & 0.7730 & 0.6040 & 0.6670 & 118.1100 & 99.2900 \\
\hline Difference & 0.0050 & -0.0040 & -0.0090 & 0.0880 & 1.6000 & -1.4200 \\
\hline Nadal-French & 0.7460 & 0.7220 & 0.5610 & 0.6880 & 111.7900 & 88.5500 \\
\hline Nadal-Wimb. & 0.6810 & 0.7900 & 0.6190 & 0.7560 & 115.4200 & 92.9700 \\
\hline Difference & 0.0650 & -0.0680 & -0.0580 & -0.0680 & -3.6300 & -4.4200 \\
\hline Djokovic-French & 0.6530 & 0.7110 & 0.4560 & 0.6220 & 112.8700 & 94.7800 \\
\hline Djokovic-Wimb. & 0.6350 & 0.7660 & 0.5690 & 0.7010 & 115.6700 & 99.9200 \\
\hline Difference & 0.0180 & -0.0550 & -0.1130 & -0.0790 & -2.8000 & -5.1400 \\
\hline Murray-French & 0.5350 & 0.7250 & 0.4750 & 0.7160 & 119.5800 & 90.9800 \\
\hline Murray-Wimb. & 0.5660 & 0.8330 & 0.6240 & 0.6900 & 119.0100 & 92.9700 \\
\hline Difference & -0.0310 & -0.1080 & -0.1490 & 0.0260 & 0.5700 & -1.9900 \\
\hline Soderling-French & 0.6270 & 0.7520 & 0.5740 & 0.6260 & 126.6300 & 103.7800 \\
\hline Soderling-Wimb. & 0.6230 & 0.8470 & 0.4840 & 0.8030 & 125.9200 & 105.8000 \\
\hline Difference & 0.0040 & -0.0950 & 0.0900 & -0.1770 & 0.7100 & -2.0200 \\
\hline Roddick-French & 0.6650 & 0.7070 & 0.4870 & 0.6400 & 123.0600 & 106.7700 \\
\hline Roddick-Wimb. & 0.7060 & 0.8340 & 0.5410 & 0.6440 & 123.8800 & 107.9500 \\
\hline Difference & -0.0410 & -0.1270 & -0.0540 & -0.0040 & -0.8200 & -1.1800 \\
\hline Verdasco-French & 0.7330 & 0.6670 & 0.4700 & 0.5210 & 105.2700 & 92.3300 \\
\hline Verdasco-Wimb. & 0.5710 & 0.7750 & 0.5170 & 0.5630 & 116.0000 & 103.0000 \\
\hline Difference & 0.1620 & -0.1080 & -0.0470 & -0.0420 & -10.7300 & -10.6700 \\
\hline Tsonga-French & 0.6060 & 0.7980 & 0.5250 & 0.6670 & 116.6700 & 91.9100 \\
\hline Federer-Wimb. & 0.6460 & 0.8010 & 0.5580 & 0.6560 & 119.1500 & 99.7600 \\
\hline Difference & -0.0400 & -0.0030 & -0.0330 & 0.0110 & -2.4800 & -7.8500 \\
\hline Ferrer-French & 0.6390 & 0.7050 & 0.5750 & 0.7500 & 110.6300 & 93.3900 \\
\hline Ferrer-Wimb. & 0.6450 & 0.7600 & 0.5200 & 0.6980 & 112.2700 & 97.0000 \\
\hline Difference & -0.0060 & -0.0550 & 0.0550 & 0.0520 & -1.6400 & -3.6100 \\
\hline Cilic-French & 0.5350 & 0.7110 & 0.5710 & 0.6800 & 116.1300 & 89.8300 \\
\hline Cilic-Wimb. & 0.6760 & 0.6530 & 0.4720 & 0.6740 & 113.0000 & 92.0000 \\
\hline Difference & -0.1410 & 0.0580 & 0.0990 & 0.0060 & 3.1300 & -2.1700 \\
\hline $\mathrm{t}$ & -0.0207 & -3.0686 & -0.8429 & -0.7775 & -1.3238 & -4.1201 \\
\hline 1-tailed p & 0.4920 & 0.0067 & 0.2106 & 0.2284 & 0.1091 & 0.0013 \\
\hline
\end{tabular}


Am. J. of Economics and Business Administration 3 (2): 405-409, 2011

Table 5: Regression statistics

\begin{tabular}{|c|c|c|c|c|c|c|}
\hline & & & Coefficients & Standard error & t-Stat & P-value \\
\hline \multicolumn{7}{|c|}{ French-1st serve speed and \% 1st serves In } \\
\hline Multiple R & 0.4639 & Intercept & 1.2334 & 0.4026 & 3.0635 & 0.0155 \\
\hline R Square & 0.2152 & X Variable 1 & -0.0051 & 0.0035 & -1.4810 & 0.1769 \\
\hline Adjusted R square & 0.1171 & & & & & \\
\hline Standard error & 0.0657 & & & & & \\
\hline Observations & 10 & & & & & \\
\hline \multicolumn{7}{|c|}{ Wimbledon-1st serve speed and \%1st serves In } \\
\hline Multiple R & 0.0105 & Intercept & 0.6258 & 0.4232 & 1.4788 & 0.1775 \\
\hline R Square & 0.0001 & X Variable 1 & 0.0001 & 0.0036 & 0.0298 & 0.9770 \\
\hline Adjusted R square & -0.1249 & & & & & \\
\hline Standard Error & 0.0473 & & & & & \\
\hline Observations & 10 & & & & & \\
\hline
\end{tabular}

\section{CONCLUSION}

The grass courts of Wimbledon have intentionally been slowed over the last decade in the interest of having longer rallies and presenting a more entertaining experience to the audience. It would be interesting to study the change in performance measures at Wimbledon over the last 20 years, including the number of shots per point, to see the effects of their slowing. However, there are still significant differences between these courts and the clay courts at the French Open. As expected, it is still much harder for the receiver to win points at Wimbledon than at the French and it is easier for players to hit aces and other outright winners. Because of the difficulty in breaking serve, there were more points, games and sets played per match at Wimbledon and sets were more likely to end in tiebreakers. It would be interesting to compare the total number of hits and the amount of distance covered by players in a match, though, since points at the French tend to be longer and involve more running. Despite playing fewer points, players at the French probably get much more of a workout.

Service speeds seem a bit higher at Wimbledon, especially on second serves, at least in the case of the top ten players. Yet the accuracy of first serves was actually higher at Wimbledon for the overall field and virtually identical for the top ten players. Serving speed showed no significant effect on serving accuracy for the top ten players.

Making the Wimbledon courts slower represents a marketing strategy by tournament organizers; it also has effects on players' chances of winning and therefore on their decision whether to enter the tournament. Many tennis fans decry this homogenization of the game and would prefer to watch players forced to compete under varying conditions and to see different players with different styles of play excel. As the French would say, "Vive la difference!"

\section{REFERENCES}

Harrell, E., 2008. At Wimbledon It's the Grass, Stupid. http://www.time.com/time/magazine/article/0,917, 1815724,00.html

Martin, J., 2010. Wimbledon Grass is Green but Slower. The New York. http://www.nytimes.com/2010/07/04/sports/tennis/ 04grass.html?_r=1

Roland-Garros, 2010. http://www.rolandgarros.com/en_FR/scores/extrast ats/index.html

Wimbledon Championships 2010. http://www.wimbledon.org/en_GB/scores/cmatch/ 15ms.html 